\title{
AHP-VIKOR Bridge Structural System Selection in Urban Areas Tehran: Interchanges Case Study
}

\section{Ali Akbar Ramezanianpour', Seyyed Alireza Tabatabaei ${ }^{2}$, Mahyar Pourlak ${ }^{3 *}$, Majid Abareshi $^{4}$}

'Department of Civil Engineering, Amirkabir University of Technology, Tehran, Iran

${ }^{2}$ Department of Construction Management, Islamic Azad University-South Tehran Branch, Tehran, Iran

${ }^{3}$ Young Researchers and Elite Club, South Tehran Branch, Islamic Azad University, Tehran, Iran

${ }^{4}$ Department of Industrial Engineering, Iran University of Science and Technology, Tehran, Iran

Study Area: Tehran, Iran

Coordinates: $35^{\circ} 41^{\prime} 46^{\prime \prime} \mathrm{N} ; 51^{\circ} 25^{\prime} 23^{\prime \prime} \mathrm{E}$

Key words: Analytic Hierarchy Process (AHP),

Priority weight.

\section{Abstract}

The selection of "Structural system" is one of the most important factors in any bridge and infrastructure design. Designers perform the structural calculations for the project determines the priorities as well as design and performance criteria. Further analysis of the structural selection problem and the identification of the bridge desirable capabilities, triggered the consideration of analytic hierarchy process (AHP) as a possible basis for the decision making. The methodology uses the VIKOR to evaluate the alternatives according to the decision criteria and determine the solution. The methodology was developed by a group of bridge designers involved in design and management of urban infrastructure projects and demonstrated using a Steel Girder bridge in an urban area as an optimumalternative.

structural shape. These criteria can be further divided into sub-criteria, for instance, direct and indirect costs (McCrea et al., 2002; Pan, 2006; Pan et al., 2005;; Ugwu et al., 2005; Kerzner, 2001; Ugwu et al., 2006) . While the earlier researchers have attempted to solve the selection problems employing various mathematical tools and techniques that were affected by the weights assigned to the considered selection criteria, "Multi-Objective Optimization on the basis of ratio analysis" (MOORA) and "Preference Ranking Organization Method for Enrichment Evaluations" are now using successfully for the grouping and comparing the desired criteria of bridge selection that would remain unaffected by the criteria weights and normalization procedure (Choi et al., 2012; Jung \& Lee, 2012; Mandal \& Sarkar, 2012).

Attempts were also made to integrate different decision support systems to prioritize of evaluation criteria and to rank the bridge design alternatives. Examples include Project Resource Planning, Fuzzy Analytic Hierarchy Process and Analytic Network Process (Vayvay et al., 2012; Al-Harbi, 2001; Felek et al., 2002; Basligil, 2005).

Malekly et al. (2010) developed an integrated methodology using "Quality Function Deployment" and "Technique for Order Performance by Similarity to Ideal Solution" (TOPSIS) for evaluating conceptual bridge have focused on the decision criteria such as quality, required construction period, safety, and 
design. Along with the availability of more advanced construction applications, the selection of appropriate construction method becomes vital in bridge engineering domain (Skibniewski, 1992; Hastak,1998). However, there have been relatively few studies that adopted MCDM optimization and AHP in the field of bridge selection (Eshtehardian et al., 2013; Farkas, 2010; Golestanifar \& Ahangari, 2011; Wang, 2011). Rashidi \& Gibson (2011) proposed a methodology for bridge condition assessment, which used AHP method to evaluate random vector parameters in the transportation area.

Analytic Hierarchy Process (AHP) as one of the multi criteria decision making tools, firstly sets on by Saaty (1980). AHP has been one of the most extensively used methods for MCDM and has been extensively studied and refined since then. It provides a comprehensive and rational framework for structuring a decision problem, for representing and quantifying its elements, relating these elements to overall goals, and for evaluating alternative solutions. AHP has been used to solve MCDM problems in a wide variety of areas such as project selection, budget allocation (Soh, 2010), and software selection (Štemberger, 2009). It is mainly used to derive the most advanced scales of measurement from both discrete and continuous paired comparisons in multilevel hierarchic structures. These comparisons may be taken from actual physical measurements or from subjective estimates that reflect the relative strength of preferences of the experts. (Farkas, 2010).

The AHP methodology, as its name implies, requires a hierarchy structure to represent the decision problem, as well as pairwise comparisons to establish relations within the structure. The pairwise comparisons lead to dominance matrices. The required number of these matrices corresponds to the number of weighting factors. Regarding the group participants, it is necessary to find out how close (or far apart) an individual's judgment is to others, so they can be synthesized. Synthesizing the judgments of decision makers based on the average weighting factors, will lead to a weighted priority ranking that indicates the overall preference score for each decision alternative (Farkas, 2010). A fuzzy-AHP method is one of the most appropriate techniques for selecting the suitable bridge construction method, particularly for segmental and precast concrete segment bridges. In this study, eight experts (bridge design engineers) were asked to the criteria through pair-wise comparisons. This led to the development of an AHP model including two hierarchies, three choices, and 5 criteria (Quality, Cost, Safety, Timeand Shape) (Pan, 2008).

VIKOR is an adaptive MADM method that is developed by Opricovic \& Tzeng (2007) based on the LPmetric. This method is based on the adaptive planning of MCDM problems and evaluates problems where decision criteria are inappropriate and inconsistent. The VIKOR method is well established in situations where the decision maker has to deal with such criteria and thus inevitably seeks solutions close to the ideal. In this method, all decision alternatives are evaluated against the decision criteria. Moreover, this method is particularly useful in cases where the decision maker is not able to identify the superiorities of a problem upon its starting time and planning phase. In such cases, the VIKOR method serves as an effective decision making tool and provides a maximum group utility value for the majority and a minimum individual regret for the veto (Opricovic \& Tzeng, 2007).

The VIKOR method delivers relative satisfaction of the majority of decision criteria in terms of their closeness to the ideal solution and entails minimum levels of regret for each of the criteria in terms of their closeness to antiideal solutions. In other words, minimum regret in having failed to choose the ideal solution. Here, the decision alternative with the highest rank is the one that is closest to the ideal solution; conversely, in methods such as TOPSIS, the highest ranked decision alternative does not always represent the closest one to the ideal solution (Valahzaghard \& Ferdousnejhad, 2013). The VIKOR method has been applied to the problems of producer management and prioritization in the supply chain (Liou \& Chuang, 2010; Liu \& Du, 2008; Lixin et al., 2008; Tianchang et al., 2008) optimization of processes (Tong et al., 2007), evaluation of banking performances (Wu et al., 2009) and in earthquake and environmental engineering (Opricovic \& Tzeng, 2004). This method has also been used in urban and water resource management (Chang \& Hsu, 2009; Opricovic, 2009). For more on the applications of the VIKOR method, the interested reader may refer to (Büyüközkan \& Ruan, 2008; Chen \& Wang, 2009; Chiang, 2009; Sanayei et al., 2010).

Existing Gap in the Process: designers (usually civil/ structural engineers), performing the structural calculations for the project determine the priorities as well as design and performance criteria. Depending on the engineer's opinion, some of the essential criteria or structural systems may get ignored. This may lead to an increase in costs and reductions in efficiency. However, using the step-by-step procedure, such problems could be avoided in the early stages of major bridge projects.

Proposed Model: this section divides the model into a three-layered hierarchical model, as shown in Figure-1, where the overall objective is placed in level 1 , criteria and decision alternatives are presented in level 2 and 3, respectively.The main objective is to select the most suitable bridge structural system (decision made by the design engineer). Then, the design criteria including Project cost, Construction Duration, Traffic limitation 


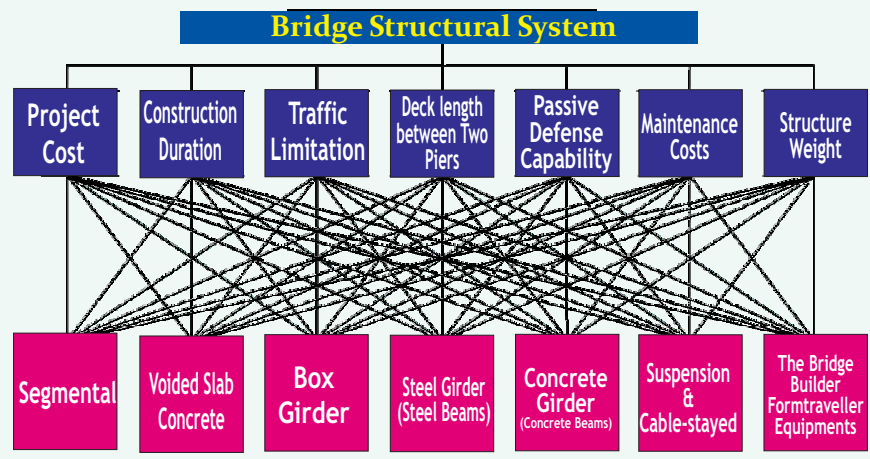

Figure 1: The Hierarchy for the Consultant Selection Problem

(especially in urban zones), Span, Passive defense capability and Maintenance costs, (level 2) will result in the design alternatives (level 3), presented in "Figure-1".

Definition of Criteria: among all the selection criteria, we only consider Project cost, Construction Duration, Traffic limitation (especially in urban zones), Span, Passive defense capability and Maintenance costs in this paper. These criteria are described in the following:

Project cost: The structure cost is affected by the project schedule, resources, and risk. The project cost can be the most important parameter describing a client's project requirements. It should be noted that this study does not take into account the mobilization cost.

Construction Duration: The construction duration arising from critical path in which duration for items of work or activity in sequences or hierarchies cannot be reduced further.

Traffic Limitation (especially in urban zones): Considering the effect of construction activities on traffic flow, the traffic volume (both vehicles and pedestrians) during the construction phase is selected as one of the selection criteria.

Deck length between Two Piers: The distance between two piers of a bridge has been considered as a uniform variable in all systems.

Passive Defense Capability: Capability of a bridge structural system is an inherent characteristic of any structure that should be considered during the design process for any critic situation.

Maintenance Costs: The maintenance costs of equipment and bridge itself during its lifespan account for a major part of total life cycle cost. Performing field inspection of the bridge can provide better insight into the detection and correction of structural components with serious defects. Maintenance, including tests, measurements, adjustments, and parts replacement, is mainly performed to prevent faults from occurring. "Figure 2" shows the importance of the maintenance costs in a bridge construction project.

Structure Weight: The weight of the structure (Piers, Abutments, and Deck), is dependent on the surface area of the structure and plays a key role in the seismic capability of the structure. Earthquake forces are proportional to a structure's mass, so heavy bridge structures experiencegreater forces.

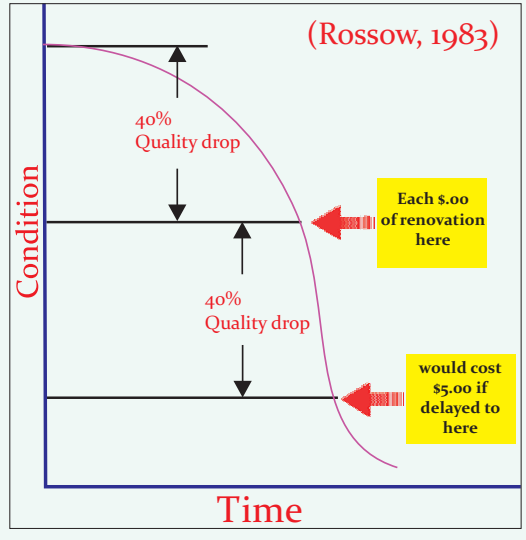

Figure 2: Cost of delaying maintenance
Decision

Alternatives: among different design alternatives, following Tahouni, (2004) the given Bridge Structural Systems have been selected for this study; Segmental bridge, Voided Slab Bridge, Box Girder Bridge, Steel Girder (Steel Beams)Bridge, Concrete Girder (Concrete Beams) Bridge, Suspension \& Cable-stayedbridge, Bridge Builder Form-traveler Equipments .

\section{Steps in the VIKOR Method:}

Calculation of the Normalized Quantities/ Values-

Assume that there are $m$ decision alternatives and $n$ decision criteria. The normalized quantities/values are calculated using the following equation.

The various alternatives, $i$, are represented as $x i$. $x i j$ is the value and amount of criteria $j$. Normalization of the quantities, where xij is the real value of alternative $i$ and then $\mathrm{j}$, is as follows:

$$
f_{i j}=\frac{x_{i j}}{\sqrt{\sum_{j=1}^{n} x_{i j}^{2}}}, i=1,2, \ldots, m ; \quad j=1,2, \ldots, n
$$

Where, $x i j$ is the value of alternative i for criterion $j$.

\section{Determination of the Bestand Worst Values}

The best and worst values for each criterion are identified and called fj*and fj-, respectively.

$$
\begin{array}{lll}
f_{j}^{*}= & \operatorname{Max}_{i j} & , i=1,2, \ldots, m \\
f_{j}^{-}= & \operatorname{Min} f_{i j} & , j=1,2, \ldots, n
\end{array}
$$

Where $f j$ * is the best positive ideal solution and $f j$ is the worst negative ideal solution for criterion $j$. Combining all $f j^{*}$, an optimum combination result which yield the highest rank. This also holds true for $f j$-.

$$
\begin{aligned}
& S_{i}=\sum_{j=1}^{n} w_{i}\left(f_{j}^{*}-f_{i j}\right) /\left(f_{j}^{*}-f_{j}^{-}\right) \\
& R_{i}=\operatorname{Max}\left[w_{i}\left(f_{j}^{*}-f_{i j}\right) /\left(f_{j}^{*}-f_{j}^{-}\right)\right]
\end{aligned}
$$

Where $S i$ is the distance between alternative $i$ and the positive ideal solution (best combination) and $\mathrm{Ri}$ is the distance between alternative $i$ and the negative ideal solution (worst combination). The best and worst ranks are then computed based on the values of $S_{i}$ and $R_{i}$, respectively. In other words, $S_{i}$ and $R_{i}$ are Lii and Lor equivalents in the LP-metric technique.

\section{Calculating the VIKOR value Qi}

The VIKOR value is calculated for every i as follows: 


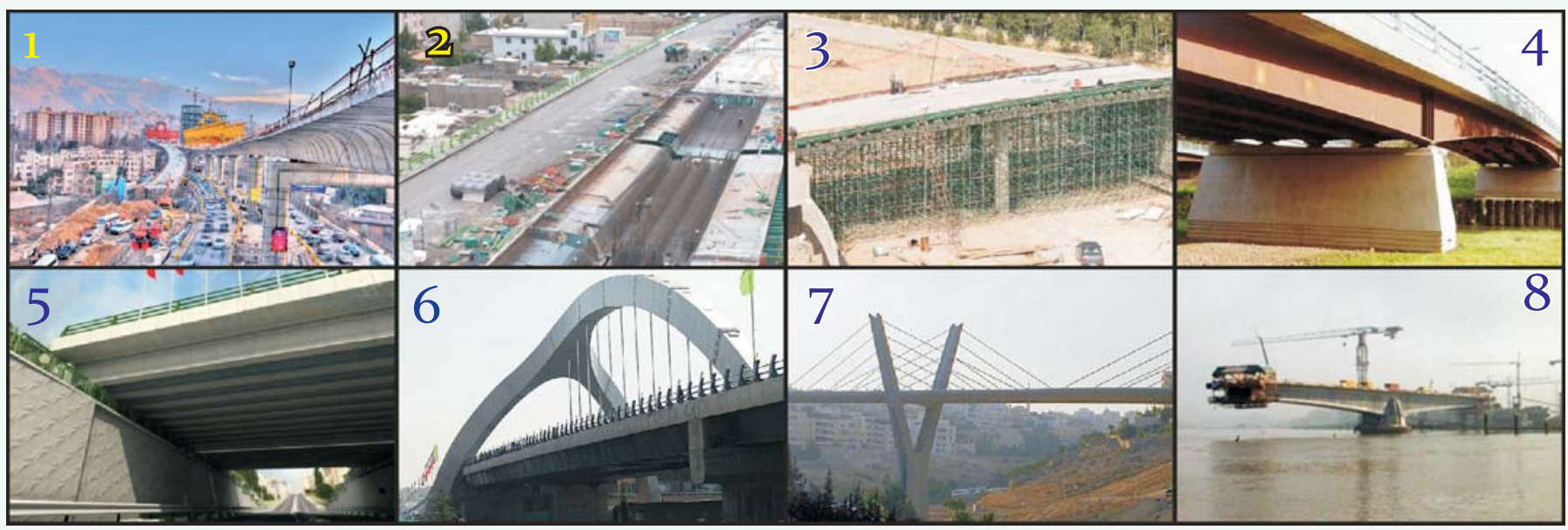

Figures: (3-10): 3- Sadr Elevated Expressway, Under Construction (2012), Tehran, IRAN; 4- The Vafadar Bridge, Constructed (2012), Tehran, IRAN; 5- Abbaspour University Box Girder Bridge, Constructed (2012) Tehran, IRAN; 6- Steel Multi-girder bridge using variable depth girders Westgate bridge, Gloucester; 7- Sazman Aab Bridge, Constructed (20o8), Tehran IRAN; 8- : Javadieh Bridge, Constructed (2010), Tehran, IRAN; 9- Abdoun Bridge, Constructed (2006), Amman, Jordan; 10- Pierre Pflimlin bridge being built over the Rhine south of Strasbourg

$$
\begin{aligned}
& Q_{i}=v\left[\frac{S_{i}-S^{-}}{S^{*}-S^{-}}\right]+(1-v)\left[\frac{R_{i}-R^{-}}{R^{*}-R^{-}}\right] \\
& \text {Where } \\
& \qquad S^{-}=\operatorname{Min} S_{i} \quad S^{*}=\operatorname{Max}_{i} \quad R^{-}=\operatorname{Min}_{i} \text { and } R^{*}=\operatorname{Max}_{i} R_{i}
\end{aligned}
$$

and $v$ is the maximum group utility or the strategy weight of the majority that vote in favour of the given criteria.

$\left[S_{i}-S^{-}\right]$is the distance from alternative $\mathrm{i}$ to the negative

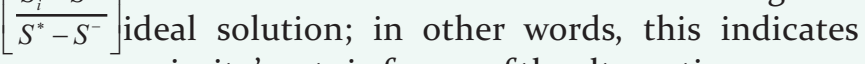
majority's vote in favour of thealternative.

$\left[\frac{R_{i}-R^{-}}{R^{-}-R^{-}}\right]$is the distance from alternative $\mathrm{i}$ to the positive $\left[\frac{R^{*}-R^{-}}{R^{-}}\right.$ideal solution; This distance value is the majority's vote against alternative i. So, when

$v>0.5$ holds true, Qi leads to a majority agreement/ satisfaction, conversely, when $v<0.5$ holds true, Qi represents the negative view of the majority. Finally, when $=0.5$ holds true then this means that a consensus is reached between the evaluation experts.

\section{Ranking of the Alternatives Based on Qi}

In this step, the alternatives are ranked based on the values of $\mathrm{Q}_{\mathrm{i}}$ that were calculated in the previous step and then the decision can be made.

\section{Case study}

In this section, an AHP-based selection model for the bridge structure is formulated and then applied to a real case study.

The alternatives are organized and ranked according to their values, their ascending rank. Each alternative must satisfy the following two conditions:

Condition 1: If alternatives 1 and 2 -in order- are first and second best alternative in the group and $\mathrm{n}$ shows the number of alternatives. Then :

$$
\mathrm{Q}\left(\mathrm{A}_{2}\right)-\mathrm{Q}\left(\mathrm{A}_{1}\right) \geq \frac{1}{\mathrm{n}-1}
$$

Regarding the values and ranks of $\mathrm{R}, \mathrm{S}$ and $\mathrm{Q}$ groups, the selection should be processed towards "Concrete Girder" and "Steel Girder" by checking out two mentioned conditions.

$\mathrm{Q}($ steel Girder $)-Q($ concrete Girder $) \frac{\geq 1 \rightarrow 0.0273741030 .166666667}{7^{-1}}$

The objective, affected by the selection criteria, is placed at the top of the hierarchy. These criteria are presented on the second level and the design alternatives are presented at the bottom of the hierarchy. These alternatives are affected by sub-criteria and if there is no sub-criterion, they are affected by main criteria.

After defining the relative importance of all the decision criteria via pair-wise comparisons, the result is represented in a comparison matrix. The Scales of Relative Importance are simply followed "Table-1" rules.

Table -1: Scale of Relative Importance

\begin{tabular}{lc}
\hline The importance of pairwise comparison & Numerical value \\
\hline Rather uniform & 1 \\
Identical or partially reference & 2 \\
Relatively reference & 3 \\
Moderately or strongly reference & 4 \\
Strongly reference & 5 \\
Strong tovery strong reference & 6 \\
Very strong preference & 7 \\
A reference to the immensely & 8 \\
Thesize of the reference & 9 \\
\hline
\end{tabular}

In the first step, we interviewed total eight design engineers for obtaining the required information regarding the mean criteria matrix. Table 2 shows the comparison matrix for the criteria defined in this study. This matrix results from the relative weights among all the possible combinations of the selection criteria.

The relative weights are determined after the normalization of the matrix. This process is performed by dividing the elements of each column with their sum. As a 
result, we compared the decision criteria and calculate their relative weights. Although this matrix should fulfill the client's needs and requirements, we completed that based on the interviewed experts. The experts' knowledge and opinion can also demonstrate the difference between theirviewpoints and those of clients.

The next step is to compare the decision alternatives regarding each decision criterion. This is done by using seven different tables like "Table 3", which shows an example of the comparison matrix with some decisions. Then, the weight of each alternative is calculated.

Table 2: Criteria Comparison Matrix; filled by MCDM Experts

\begin{tabular}{llllllll}
\hline & $\mathrm{a}$ & $\mathrm{b}$ & $\mathrm{c}$ & $\mathrm{d}$ & $\mathrm{e}$ & $\mathrm{f}$ & $\mathrm{g}$ \\
\hline $\mathrm{a}$ & 1.00 & 1.67 & 1.25 & 2.67 & 1.92 & 1.92 & 2.67 \\
$\mathrm{~b}$ & 0.60 & 1.00 & 1.39 & 1.83 & 1.83 & 1.72 & 1.92 \\
$\mathrm{c}$ & 0.80 & 0.72 & 1.00 & 2.50 & 1.92 & 1.83 & 2.67 \\
$\mathrm{~d}$ & 0.38 & 0.55 & 0.40 & 1.00 & 1.39 & 0.64 & 1.17 \\
$\mathrm{e}$ & 0.52 & 0.55 & 0.52 & 0.72 & 1.00 & 1.31 & 1.64 \\
$\mathrm{f}$ & 0.52 & 0.58 & 0.55 & 1.57 & 0.77 & 1.00 & 2.17 \\
$\mathrm{~g}$ & 0.38 & 0.52 & 0.38 & 0.86 & 0.61 & 0.46 & 1.00
\end{tabular}

a-Project Cost; b-Construction Duration; c-Traffic Limitation; d- Deck length; e- Passive Defense; f- Maintenance Costs; gStructure Weight
Table 3: Project Cost Comparison Matrix with Decisions

\begin{tabular}{llllllll}
\hline & $\mathrm{h}$ & $\mathrm{i}$ & $\mathrm{j}$ & $\mathrm{k}$ & $\mathrm{l}$ & $\mathrm{m}$ & $\mathrm{n}$ \\
\hline $\mathrm{h}$ & 1.00 & 0.53 & 0.75 & 0.75 & 0.53 & 1.63 & 0.88 \\
$\mathrm{i}$ & 1.89 & 1.00 & 1.42 & 1.42 & 1.17 & 2.50 & 2.00 \\
$\mathrm{j}$ & 1.33 & 0.71 & 1.00 & 1.17 & 0.97 & 2.21 & 1.63 \\
$\mathrm{k}$ & 1.33 & 0.71 & 0.86 & 1.00 & 0.69 & 2.24 & 1.65 \\
$\mathrm{l}$ & 1.89 & 0.86 & 1.03 & 1.44 & 1.00 & 2.24 & 1.90 \\
$\mathrm{~m}$ & 0.62 & 0.40 & 0.45 & 0.45 & 0.45 & 1.00 & 0.69 \\
$\mathrm{n}$ & 1.14 & 0.50 & 0.62 & 0.60 & 0.53 & 1.44 & 1.00 \\
\hline
\end{tabular}

Once all matrices are compared and formed, we can normalize each matrix. Table 4 shows the decision criteria matrix that is formed based on these thevalues.

Table 4: The matrix of Decisions-Criteria

\begin{tabular}{|c|c|c|c|c|c|c|c|}
\hline & $\mathrm{h}$ & $\mathrm{i}$ & j & $\mathrm{k}$ & 1 & $\mathrm{~m}$ & $\mathrm{n}$ \\
\hline $\mathrm{h}$ & 0.1087 & 0.1778 & 0.1795 & 0.1694 & 0.0966 & 0.1196 & 0.1509 \\
\hline $\mathrm{i}$ & 0.2097 & 0.1330 & 0.1019 & 0.0958 & 0.1885 & 0.2074 & 0.1010 \\
\hline j & 0.1631 & 0.1470 & 0.1614 & 0.1063 & 0.1754 & 0.1602 & 0.1770 \\
\hline k & 0.1495 & 0.1427 & 0.1595 & 0.1110 & 0.1728 & 0.1602 & 0.1930 \\
\hline 1 & 0.1878 & 0.1480 & 0.1531 & 0.0814 & 0.1517 & 0.1439 & 0.1174 \\
\hline $\mathrm{m}$ & 0.0742 & 0.1141 & 0.1144 & 0.2325 & 0.0980 & 0.0798 & 0.1378 \\
\hline $\mathrm{n}$ & 0.1037 & 0.1300 & 0.1236 & 0.1875 & 0.1122 & 0.1203 & 0.1174 \\
\hline
\end{tabular}

h-Segmental; i-Voided Slab ; j-Steel Girder ; k-Box Girder; 1Concrete Girder ; m- Suspension \& Cable-stayed; n- Bridge Builder Form-travele

Table 5: The matrix of Decisions-Criteria

\begin{tabular}{|c|c|c|c|c|c|c|c|c|}
\hline \multicolumn{2}{|r|}{ Criteria } & $\begin{array}{l}\text { Structure } \\
\text { Weight }\end{array}$ & $\begin{array}{l}\text { Maintenance } \\
\text { Costs }\end{array}$ & $\begin{array}{l}\text { Passive } \\
\text { Defence }\end{array}$ & $\begin{array}{l}\text { Deck } \\
\text { Length }\end{array}$ & Duration & Limitation & $\begin{array}{l}\text { Project } \\
\text { Costs } \\
\end{array}$ \\
\hline \multirow{11}{*}{ 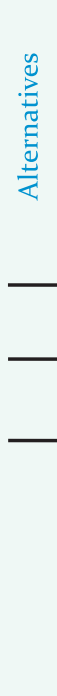 } & Criteria weights (Importance) & 0.129 & 0.07 & 0.19 & 0.057 & 0.02 & 0.091 & 0.02 \\
\hline & Voided Slab & 0.19 & 0.089249888 & 0.188533065 & 0.095780022 & 0.190216063 & 0.148821968 & 0.086032866 \\
\hline & Steel Girder & 0.11 & 0.115572398 & 0.175446833 & 0.106284896 & 0.120079488 & 0.134664752 & 0.110565971 \\
\hline & Box Girder & 0.1 & 0.115572398 & 0.172807515 & 0.110975135 & 0.121581415 & 0.138672467 & 0.120689083 \\
\hline & Concrete Girder & 0.16 & 0.128657183 & 0.151717799 & 0.081360889 & 0.126625949 & 0.133746197 & 0.096057958 \\
\hline & $\mathrm{f}^{*}$ & 0.1 & 0.09 & 0.19 & 0.23 & 0.11 & 0.11 & 0.09 \\
\hline & f- & 0.19 & 0.23 & 0.1 & 0.08 & 0.19 & 0.17 & 0.24 \\
\hline & Alternatives & Ranking & Value (Qi) & Value (Vi) & $\begin{array}{l}\text { Distance from } \\
\text { Solution (Ri) }\end{array}$ & ositive Ideal & $\begin{array}{l}\text { Distance fro } \\
\text { Ideal Solutio }\end{array}$ & $\begin{array}{l}\text { Positive } \\
(\mathrm{Si})\end{array}$ \\
\hline & Segmental & 4 & 0.555166504 & 0.5 & 0.12139812 & & 0.345546764 & \\
\hline & Suspension \& Cable-stayed & 7 & 0.5 & 0.5 & 0.244441221 & & 0.835306485 & \\
\hline & Bridge Builder Form-traveler & 6 & 0.579756231 & 0.5 & 0.134076564 & & 0.593271635 & \\
\hline
\end{tabular}

As the "Concrete Girder" does not satisfy the above condition, it cannot be the best alternative. In the case study, "Steel Girder" alternative satisf ied both conditions and resulted in the best alternative. To analyze the problem according to the AHP approach, we need to multiply the matrix shown in Table 4 by the one shown in Table 5 . Because the sizes of the matrices are $7 \times 7$ and $7 \times 1$, the resulting matrix is $7 \times 1$ (Table 6 and Figure 11). Table 7 shows the resulting ranking of the alternatives.

Results :

Regarding last part, now alternatives should be ranked relies on $\mathrm{R}, \mathrm{S}$, and Qvalues; then: 


\begin{tabular}{|c|c|c|c|c|c|}
\hline \multicolumn{2}{|c|}{ Rely on Q value } & \multicolumn{2}{|c|}{ Rely on R value } & \multicolumn{2}{|c|}{ Rely on Q value } \\
\hline 0.472625897 & Concrete Girder & 0.076455934 & Steel Girder & 0.254193866 & Steel Girder \\
\hline 0.5 & Steel Girder & 0.086208552 & Box Girder & 0.27801527 & Box Girder \\
\hline 0.5 & $\begin{array}{l}\text { Suspension \& } \\
\text { Cable-stayed }\end{array}$ & 0.091858971 & Concrete Girder & 0.339292566 & Steel Girder \\
\hline 0.508531816 & Box Girder & 0.12139812 & Segmental & 0.345546764 & Segmental \\
\hline 0.579756231 & $\begin{array}{l}\text { Bridge Builder } \\
\text { Form-traveler Eqp. }\end{array}$ & 0.134076564 & $\begin{array}{l}\text { Bridge Builder } \\
\text { Form-traveler Eqp. }\end{array}$ & 0.458665828 & Voided Slab \\
\hline 0.555166504 & Segmental & 0.190412881 & Voided Slab & 0.593271635 & $\begin{array}{l}\text { Bridge Builder } \\
\text { Form-traveler Eqp. }\end{array}$ \\
\hline $\begin{array}{l}\text { o.663255841 } \\
\text { Concrete Girder }\end{array}$ & Voided Slab & 0.244441221 & $\begin{array}{l}\text { Suspension \& } \\
\text { Cable-stayed }\end{array}$ & 0.835306485 & $\begin{array}{l}\text { Suspension \& } \\
\text { Cable-stayed }\end{array}$ \\
\hline
\end{tabular}

\begin{tabular}{|c|c|c|c|}
\hline & \multicolumn{2}{|c|}{0.1412} \\
\hline & ided Slab & \multicolumn{2}{|c|}{0.1512} \\
\hline \multicolumn{2}{|c|}{ Steel Girder } & \multicolumn{2}{|c|}{0.1540} \\
\hline \multicolumn{2}{|c|}{ Box Girder } & \multicolumn{2}{|c|}{0.1510} \\
\hline \multicolumn{2}{|c|}{ Concrete Girder } & \multicolumn{2}{|c|}{0.1472} \\
\hline \multicolumn{2}{|r|}{ Suspension \& Cable-stayed } & \multicolumn{2}{|c|}{0.0293} \\
\hline \multicolumn{2}{|r|}{ Bridge Builder Form-traveler Eqp. } & \multicolumn{2}{|c|}{0.1219} \\
\hline \multicolumn{4}{|c|}{ Table 7: Ranked Result Matrix } \\
\hline & Steel Girder & & 0.154 \\
\hline & Voided Slab & & 0.1512 \\
\hline & Box Girder & & 0.1510 \\
\hline & Concrete Girder & & 0.1472 \\
\hline & Segmental & & 0.1412 \\
\hline & The Bridge Builder Form-travel & & 0.1219 \\
\hline 7 & Suspension \& Cable-stayed & & 0.0293 \\
\hline
\end{tabular}

\section{Conclusion:}

Bridge construction decisions during the design and construction stages of a project became more complex as new construction methods have been developed. The diversity and complexity of the construction methods demonstrate the need for using a uniform and systematic way to select the best decision alternative. The MCDM approaches are the ones that quantify the decision criteria and alternatives.

In this paper, we used AHP and VIKOR techniques for evaluating five different bridge structural systems; Steel Girder, Voided Slab, Box Girder, Concrete Girder, Segmental, Bridge Builder Form-traveler Equipment and Suspension \& Cable- stayed. Also, the experts' opinions were utilized for the evaluation of each alternative and its relative weight. Through a case study, the application of the method was presented and "Steel Girder" system was selected as the bestalternative.

Acknowledgements:We wish to thank Mr. Shapour Tahouni, Assistant Professor in department of civil engineering Amirkabir University of Technology for his assistance and consultant in this research.

\section{References:}

Al-Harbi, K. (2001): Application of AHP in project management. Int. J. Proj. Manag., 19(1):19-27.

Arici, Y. \& Mosalam, K. (200o): System identification and modeling of bridge systems for assessing current design procedures. in Proceedings of SMIP Seminar, pp. 77-95.

Basligil, H. (2005): The Fuzzy Analytic Hierarchy Process for Software Selection Problems. J.Eng. Nat. Sci., 2:24-33.

Büyüközkan, G. \& Ruan, D. (2008): Evaluation of software development projects using a fuzzy multi-criteria decision approach. Math. Comp. Simul., 77: 464-475.

Chen, L.Y. \& Wang, T.C. (2009): Optimizing partners' choice in IS/IT outsourcing projects: The strategic decision of fuzzy VIKOR. Int. J. Pro. Eco., 120:233-242

Chiang, A. (2009): Developing an Online Finanical Decision Support Module Based on Fuzzy MCDM Method and Open Source Tools," in ICIFE 2009. International Conference, pp. 22-26.

Chang, C.L. \& Hsu, C.H. (2009): Multi-criteria analysis via the VIKOR method for prioritizing land-use restraint strategies in the Tseng-Wen reservoir watershed," L. Environ. Manag., 90:3226-3230.

Choi, S.J., Kim, J.H. \& Lee, D.R. (2012): Decision of the water shortage mitigation policy using Multi-Criteria Decision Analysis. KSCE J. Civil Eng., 16:247-253.

Eshtehardian, E., Ghodousi, P. \& Bejanpour, A. (2013): Using ANP and AHP for the Supplier Selection in the Construction and Civil Engineering Companies; Case Study of Iranian Company. KSCEJ. Civil Eng., 17:262-270.

Farkas, A. (2010): The Use of the AHP in Civil Engineering Projects, in MEB- 8th International Conference on Management, Enterprise and Benchmarking, Budapest, Hungary, 2010.

Felek, S., Yulugkural, Y. \& Aladag, Z. (2002): Mobil iletisim sektöründe pazar paylasiminin tahmininde AHP ve ANP yöntemlerinin kiyaslanmasi. Endüstri Mühendisligi Dergisi, 18: 6-22.

Golestanifar, M. \& Ahangari, K. (2011): Decision on Coarse Aggregates Borrow Sources of Concrete. KSCE J. Civil Eng., 15:965-973.

Hastak, M. (1998): Advanced automation or conventional construction process. Autom. Const., 7:299-314.

Itoh, Y., Sunuwar, L., Hiranou, T., Hammad, A. \& Nishido, T. (2000): Bridge type selection system incorporating 
environmental impacts. J. Global Environ. Eng., 6:81-101.

Jung, I.S. \& Lee, C.S. (2012): Fuzzy inference and AHP-based alternative evaluation tool in the development of sustainable residential land. KSCEJ. Civil Eng., 16:273-282.

Kerzner, H. (2001): A system approach to planning, scheduling, and controlling," 7th Ed. John Wiley \& Sons.

Liou, J.J. \& Chuang, Y.T. (2010): Developing a hybrid multi-criteria model for selection of outsourcing providers. Exp. Syst. Appl., 37:3755-3761.

Liu, P. \& Du, H. (2008): The Research of Supplier Selection Based on Hybrid Decision-Making Index and VIKOR Method," in Electronic Commerce and Security, International Symposium on, 2008, pp. 661-664.

Lixin, D., Ying, L. \& Zhiguang, Zh. (20o8): Selection of logistics service provider based on analytic network process and VIKOR algorithm," in ICNSC 2008. IEEE International Conference, pp. 1207-1210.

Malekly, H., Mousavi, S.M. \& Hashemi, H. (2010): A fuzzy integrated methodology for evaluating conceptual bridge design," Expert Systems with Applications, 37(7):4910-4920

Mandal, U.K. \& Sarkar, B. (2012): Selection of Best Intelligent Manufacturing System (IMS) Under Fuzzy Moora Conflicting MCDM Environment. Int. J. Emer. Tech. Adv. Eng., 2(9):301-310.

McCrea, A., Chamberlain, D. \& Navon, R. (2002): Automated inspection and restoration of steel bridges-a critical review of methods and enabling technologies. Autom. Cons.,11:351-373.

Opricovic, S. \& Tzeng, G.H. (2007): Extended VIKOR method in comparison with outranking methods. Eur. J. Operat. Res. 178:514-529.

Opricovic, S (2009): A compromise solution in water resources planning. Water Resc. Manag., 23:1549-1561.

Opricovic, S. \& Tzeng, G.H. (2004): Compromise solution by MCDM methods: A comparative analysis of VIKOR and TOPSIS. Eur.J. Operat. Res., 156:445-455.

Pan, N.F. (2008): Fuzzy AHP approach for selecting the suitable bridge construction method. Autom. Const., 17: 958-965.

Pan, N.F. (2006): Evaluation of building performance using fuzzy FTA. Const. Manag. Econ., 24:1241-1252.

Pan, N.F., Hadipriono, F.C. \& Whitlatch, E. (2005): A fuzzy reasoning knowledge-based system for assessing rain impact in highway construction scheduling: Part 1. Analytical model.J. Int. Fuzzy Syst., 16:157-167.
Rashidi, M \& Gibson, P. (2011): Proposal of a Methodology for Bridge Condition Assessment. Australasian Transport Research Forum. p 1-13.

Rossow, M. (1983): FHWA Bridge Maintenance: Overview," vol. Course No:So2-012.

Sanayei, A., Mousavi, S.F., \& Yazdankhah, A. (2010): Group decision making process for supplier selection with VIKOR under fuzzy environment. Exp. Syst. App., 37:24-30.

Saaty, T.L. (1980): The Analytic Hierarchy Process: Planning, Priority Setting, Resource Allocation. New York: McGraw-Hill.

Skibniewski, M.J. (1992): Evaluation of advanced construction technology. L. Const. Eng. Manag., 118(3): 577-593.

Soh, S. (210): A decision model for evaluating third-party logistics providers using fuzzy analytic hierarchy process. Afr. J. Bus. Manag., 4:339-349.

Tahouni, Sh. (2004): Bridge design. Vol.1 \& 2, Tehran University Publication

Tianchang, L., Zhiwei Z. \& Lin, Z. (2008): Evaluation and selection of suppliers in supply chain based on RST and VIKOR algorithm," in Control and Decision Conference, 2008. CCDC 2008., pp. 1913-1916.

Tong, L.I., Chen, Ch. \& Wang, C. (2007): Optimization of multiresponse processes using the VIKOR method. Int. J. Adv. Manuf. Tech., 31:1049-1057.

Ugwu, O., Kumaraswamy, M.M., Kung, F. \& Ng, S.T. (2005): Object-oriented framework for durability assessment and life cycle costing of highway bridges. Autom. Cons., 14:611-632.

Ugwu O. O, Kumaraswamy M. M, Wong A, \& Ng T (2006): Sustainability Appraisal in Infrastructure Projects (SUSAIP): Part 1- Development of Indicators \& Computational Methods. Autom. Cons., 15(2):239-251

Valahzaghard, M.K. \& Ferdousnejhad, M (2013): Ranking insurance firms using AHP and Factor Analysis. Manag. Sci. Lett., 3(3):937-942.

Vayvay, O., Ozcan, Y. \& Cruz-Cunha, M.M. (2012): ERP consultant selection problem using AHP, fuzzy AHP and ANP: A case study in Turkey," E3 J. Bus. Manag. Eco., 3:106-117.

Wang, Z.Z, Fan, L.C., \& Hastak, M. (2011): Multi-Criteria Optimization of Bridge Management. Adv.Mater.Res, 255260:4080-4084

Wu, H.Y., Tzenga, G. \& Chen, Y., (2009): A fuzzy MCDM approach for evaluating banking performance based on Balanced Scorecard. Expert Syst. Appl., 36:10135-10147. 